\title{
Plasticity Beyond V1: Reinforcement of Motion Perception upon Binocular Central Retinal Lesions in Adulthood
}

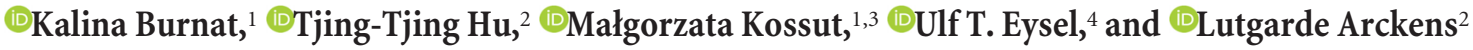 \\ ${ }^{1}$ Laboratory of Neuroplasticity, Department of Molecular and Cellular Neurobiology, Nencki Institute of Experimental Biology, Polish Academy of Sciences, \\ 02-093 Warsaw, Poland, ${ }^{2}$ Laboratory of Neuroplasticity and Neuroproteomics, KU Leuven, 3000 Leuven, Belgium, ${ }^{3}$ Department of Psychology, SWPS \\ University of Social Sciences and Humanities, 03-815 Warsaw, Poland, and ${ }^{4}$ Department of Neurophysiology, Medical School, Ruhr-Universität Bochum, \\ D-44780 Bochum, Germany
}

Induction of a central retinal lesion in both eyes of adult mammals is a model for macular degeneration and leads to retinotopic map reorganization in the primary visual cortex (V1). Here we characterized the spatiotemporal dynamics of molecular activity levels in the central and peripheral representation of five higher-order visual areas, V2/18, V3/19, V4/21a,V5/PMLS, area 7, and V1/17, in adult cats with central $10^{\circ}$ retinal lesions (both sexes), by means of real-time PCR for the neuronal activity reporter gene zif268. The lesions elicited a similar, permanent reduction in activity in the center of the lesion projection zone of area V1/17, V2/18, V3/19, and V4/21a, but not in the motion-driven V5/PMLS, which instead displayed an increase in molecular activity at 3 months postlesion, independent of visual field coordinates. Also area 7 only displayed decreased activity in its LPZ in the first weeks postlesion and increased activities in its periphery from 1 month onward. Therefore we examined the impact of central vision loss on motion perception using random dot kinematograms to test the capacity for form from motion detection based on direction and velocity cues. We revealed that the central retinal lesions either do not impair motion detection or even result in better performance, specifically when motion discrimination was based on velocity discrimination. In conclusion, we propose that central retinal damage leads to enhanced peripheral vision by sensitizing the visual system for motion processing relying on feedback from V5/PMLS and area 7.

Key words: extrastriate cortex; feedback; perceptual recovery; velocity perception; zif268

Significance Statement

Central retinal lesions, a model for macular degeneration, result in functional reorganization of the primary visual cortex. Examining the level of cortical reactivation with the molecular activity marker zif268 revealed reorganization in visual areas outside V1. Retinotopic lesion projection zones typically display an initial depression in zif268 expression, followed by partial recovery with postlesion time. Only the motion-sensitive area V5/PMLS shows no decrease, and even a significant activity increase at 3 months post-retinal lesion. Behavioral tests of motion perception found no impairment and even better sensitivity to higher random dot stimulus velocities. We demonstrate that the loss of central vision induces functional mobilization of motion-sensitive visual cortex, resulting in enhanced perception of moving stimuli.

\section{Introduction}

Extensive research has provided indisputable evidence that the mammalian brain remains plastic throughout life in response to

Received May 5, 2017; revised Aug. 3, 2017; accepted Aug. 8, 2017.

Author contributions: K.B., T.-T.H., M.K., U.T.E., and L.A. designed research; K.B., T.-T.H., and U.T.E. performed research; K.B., T.-T.H., and L.A. analyzed data; K.B., T.-T.H., M.K., U.T.E., and L.A. wrote the paper.

This work was supported by grants of the Fund for Scientific Research-Flanders (FWO-Vlaanderen), the Research Council of the KU Leuven (OT 09/22), the National Science Centre, Poland Grants N N401 557640 and 2015/19/B/ NZ4/03045 to K.B., and the German Research Foundation (DFG SFB 874 A2) to U.T.E. We thank Ria Vanlaer for excellent technical assistance.

The authors declare no competing financial interests.

Correspondence should be addressed to Dr. Kalina Burnat, Laboratory of Neuroplasticity, Department of Molecular and Cellular Neurobiology, Nencki Institute of Experimental Biology, Polish Academy of Sciences, 3 Pasteur Street, 02-093 Warsaw, Poland. E-mail: K.Burnat@nencki.gov.pl. changes of sensory input (Eysel et al., 1980; Kossut et al., 1988; Kaas et al., 1990; Chino et al., 1992; Gilbert and Wiesel, 1992; Buonomano and Merzenich, 1998; Sammons and Keck, 2015). Induction of matching central retinal lesions in both eyes of highly binocular mammals is an extensively studied animal model for the effects of vision loss as in age-related macular degeneration (AMD) syndrome patients. AMD is one of the leading causes of blindness worldwide. It affects the central retina and damages on average $10 \%$ of the central visual field. In AMD patients and animal models, loss of central visual inputs leads to 
retinotopic map reorganization in the primary visual cortex (Gilbert and Li, 2012). Upon instant deactivation of the cortical lesion projection zone (LPZ), due to retinal lesion induction, visual activity recovers during the months following the lesion due to reactivation of neurons from the border of the LPZ inward, as shown electrophysiologically in the form of a topographic map reorganization of the sensory-deprived LPZ of area V1/17 (Kaas et al., 1990; Chino et al., 1992; Gilbert and Wiesel, 1992; DarianSmith and Gilbert, 1995; Eysel et al., 1999; Giannikopoulos and Eysel, 2006; Abe et al., 2015). The recovery depends on many factors including age at lesion induction, the retinal location and size of the lesion, and becomes incomplete once the lesions exceed $5^{\circ}$ of the central visual field (Dreher et al., 2001; Waleszczyk et al., 2003; Hu et al., 2009).

Most of the plasticity research focused on the primary visual cortex (V1) and recognized intra-areal horizontal fibers as the principal anatomical substrate for this type of cortical reorganization (Gilbert and Li, 2012; Sammons and Keck, 2015). Because top-down feedback connections from extrastriate visual areas sculpt V1 receptive visual fields (Angelucci and Bullier, 2003; Gilbert and Sigman, 2007) higher-order areas may have an impact on the plasticity process. We subjected adult cats to binocular central retinal lesions, and analyzed the temporal deactivation and reactivation occurring in visual areas 17, 18, 19, 21a, and posteromedial lateral suprasylvian area (PMLS), the cat homologues of primate cortical areas V1, V2, V3, V4, and V5, respectively (Payne, 1993; Lomber, 2001; but see Connolly et al., 2012). We applied real-time PCR to quantify the expression level of the molecular activity reporter gene zif268 (Hu et al., 2009). Each visual area showed a significantly lower expression level of zif268 for its central LPZ compared with peripheral visual field representation, but not V5/PMLS, which exhibited an increase in neuronal activity in central as well as peripheral visual field representations, as registered with zif268. The features of V5/PMLS neurons identify PMLS as the motion-sensitive homolog of primate cortical area V5 (MT; Payne, 1993; Villeneuve et al., 2006). To corroborate this result associated with motion perception, we investigated area 7, located at the crown of the suprasylvian gyrus, between area 19 and PMLS. Area 7 receives visually driven input from all areas investigated in this study, but not from V5/PMLS, and direct input from the pulvinar (Olson and Lawler, 1987). This area is motion sensitive (Pigarev and Rodionova, 1998) and strongly visually driven, as shown by metabolic mapping (Vanduffel et al., 1995). The zif268 signal in area 7 returned to normal levels in the central visual field representation soon after lesioning, and an increase in neural activity was observed in its peripheral visual field representation, just like for area V5/PMLS.

We therefore elaborated the functional relevance of the area 7 and V5/PMLS-specific hyperactivity by behavioral testing of motion perception using random dot kinematograms. We observed that retinal lesions did not impair motion perception, and even enhanced motion detection and velocity discrimination, thereby sensitizing the visual system for motion analysis. Induction of central retinal lesions in adult subjects thus shifts the centralperipheral balance in visual processing, established in the course of development, and removes central dominance over peripheral visual processing.

\section{Materials and Methods}

\section{Animals}

Experiments were carried in accordance with the European Communities Council Directive of November 24th 1986 (86/609/EEC) and were approved by the Institutional Ethical Committee of KU Leuven (Bel- gium) and by the First Ethical Commission in Warsaw (Poland). Adult cats used for zif268 mRNA expression analysis $(n=15,9$ males and 6 females) were housed in the Animal Facilities of KU Leuven and exposed to a normal light environment ( $14 \mathrm{~h}$ light/10 h dark) with access to food and water ad libitum. Retinal lesioned subjects recovered for different survival times after lesioning: $14 \mathrm{~d}(14 \mathrm{~d}, n=3), 1$ month $(1 \mathrm{~m}, n=3)$, 3 months $(3 \mathrm{~m}, n=5)$ or 8 months ( $8 \mathrm{~m}, n=3$; Fig. 2 , marked in shades of gray). The $14 \mathrm{~d}$ time point was chosen as the first experimental condition because previous investigations have shown a maximal molecular response at that time point (Arckens, 2006). A survival time $<14 \mathrm{~d}$ was not included because of the effect of retinal edema in the first days after the lesions (Eysel et al., 1980; visible as a white rim surrounding the lesion, Fig. $1 B$, inset). The 8 -month time point was chosen because connectional changes have so far only been documented for this long survival time (Darian-Smith and Gilbert, 1995). Three extra animals served as controls and received no visual manipulation. Part of the molecular data collected from these animals was published earlier (Hu et al., 2009, 2011).

All cats participating in motion training $(n=12,10$ males and 2 females) were raised in the Animal Facilities of the Nencki Institute of Experimental Biology. Training started when the animals were 8 months old. Two cats participating in a pilot study were subjected to lesions after 1 year of motion training (Zapasnik and Burnat, 2013). Control cats (control, $n=6$ ) completed motion training in 3 months' time. These same animals were then subjected to binocular central retinal lesions, and, after $14 \mathrm{~d}$ of recovery, their motion performance was verified [except for 1 cat; retinal lesion trained cats (RLTrained), $n=5]$. Retinal lesioned naive cats (RLNaive, $n=4$ ) first received retinal lesions and were then trained for 3 months, following the same schedule of motion training as the controls (Timeline of training, Fig. $3 A$ ).

\section{Induction of retinal lesions}

The homonymous central retinal lesions were induced by photocoagulation (LOG-2 Xenon light photocoagulator, Clinitex) under ketamine/ xylazine anesthesia ( $0.5 \mathrm{ml}$ Ketalar, $0.2 \mathrm{ml}$ Rompun, i.m.). Nictitating membranes were retracted with phenylephrine hydrochloride (5\%), and pupils were widened with atropine sulfate (1\%). Circular lesions with sharp borders and $\mathrm{a} \approx 10^{\circ}$ diameter were centered over the area centralis, as verified by fundus photography (Fig. $1 A, B$, insets, prior and postlesion, respectively). This type of lesioning destroys all retinal cell layers (Eysel et al., 1981), and spares optic nerve fibers and retinal ganglion cells encircling the lesion site (Fig. 1B). Starting from the first postlesion day the retinal lesioned cats were observed behaviorally. Behavioral consequences of edema, such as difficulties in depth perception vanished after 4 d postlesion, consistent with Giannikopoulos and Eysel (2006). Regular motion tests started at $14 \mathrm{~d}$ postlesion.

\section{Tissue sampling}

Before kill, all animals were maintained overnight in total darkness followed by a 45 min light exposure in a well-lit room to induce maximal zif268 expression in cat visual cortex (Arckens et al., 2000; Hu et al., 2009). All cats were killed with an overdose of pentobarbital (Nembutal, $60 \mathrm{mg} / \mathrm{kg}$, i.v.) under deep ketamine anesthesia (Ketalar, $10 \mathrm{mg} / \mathrm{kg}$, i.m.). Brains were immediately dissected, instantly frozen by immersion in dry ice cooled isopentane (Merck Eurolab) and stored at $-80^{\circ} \mathrm{C}$. For RNA extraction, coronal sections of $200 \mu \mathrm{m}$ were cut on a cryostat (Microm HM 500 OM, Microm) and samples of LPZ center (C) and of peripheral visual field representation $(\mathrm{P})$ of the studied regions were dissected.

The anterior-posterior coordinates for tissue sample collection were posterior (P) 5.0, P7.5, P6.5, and anterior (A) 5.0 for area V1/17, V2/18, V3/19, V4/21a, V5/PMLS, and area 7 respectively (Fig. $1 C-G$ ). The cat visual cortex map of Rosenquist (1985), complemented with observations for PMLS by Arckens et al. (2000) and Sherk (2010), was used as a guide to guarantee correct retinotopy-driven tissue sampling from all five cat visual areas. To identify the position of the center of the LPZ of these five visual areas in situ hybridization for zif268 was performed on a series of coronal sections of each cat (Fig. $1 C-G$ ). 

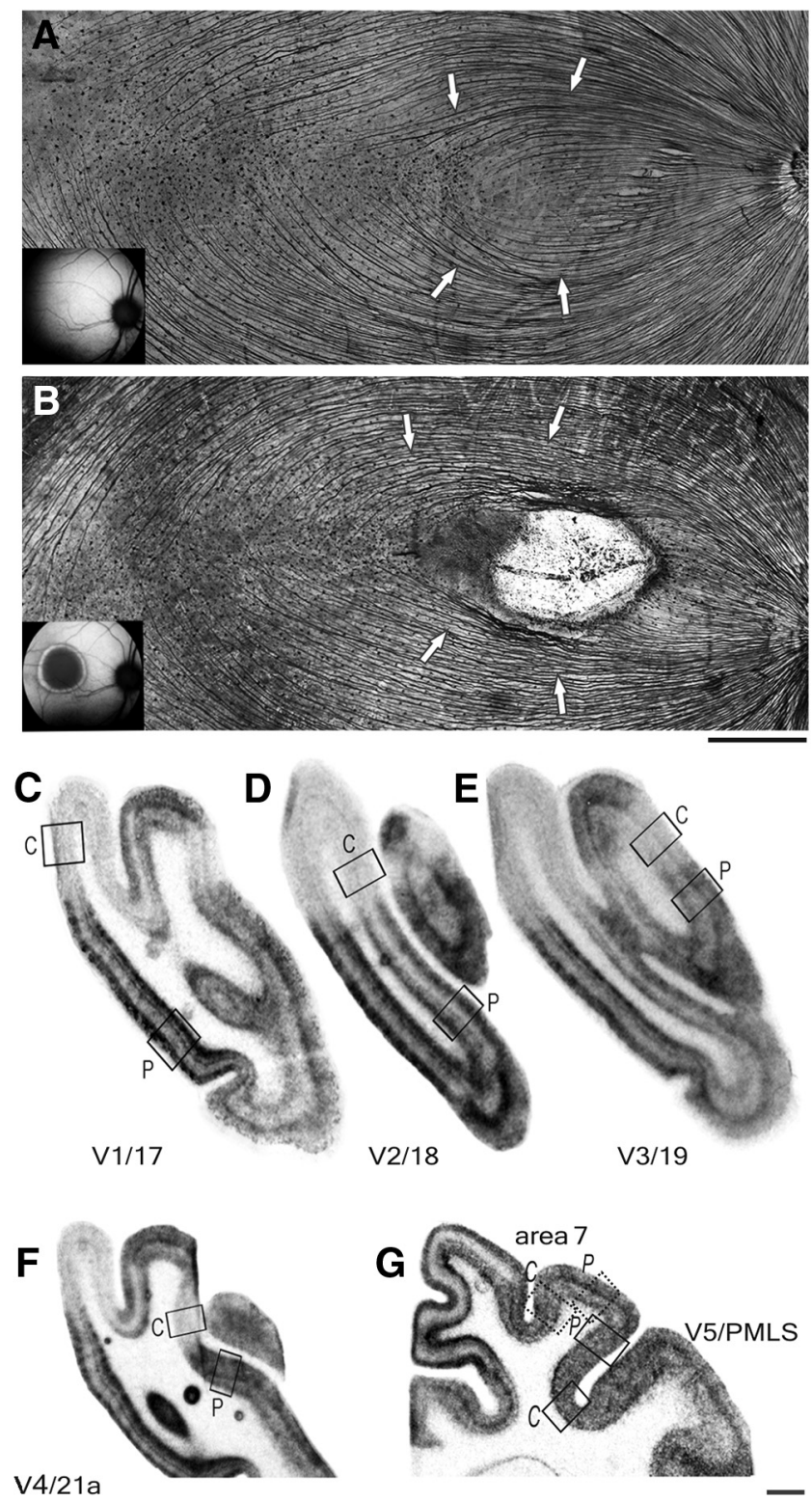

Figure 1. Retinal lesion visualization. $\boldsymbol{A}, \boldsymbol{B}$, Low-power photomicrographs of retinal whole mounts of a control and a 3 month retinal lesion cat, with insets illustrating related fundus photos taken before and after induction of the lesion. White arrows point to the SMI-32immunolabeled retinal ganglion cell axons, which encircle the area centralis, clear from such fibers, and demarcate raphe. Note the well preserved retinal ganglion cell axons encircling the lesioned, empty zone as visible on the whole-mount preparation $(\boldsymbol{B})$, and the rim of edema encircling the black lesion on the fundus photo taken directly upon lesioning ( $\boldsymbol{B}$, inset), which will disappear in ensuing days. $\mathbf{C}-\boldsymbol{F}$, Illustration of the LPZ with in situ hybridization for zif268 based on the very low expression level in the central representations of the visual field in areas $\mathrm{V} 1 / 17, \mathrm{~V} 2 / 18, \mathrm{~V} 3 / 19$, and V4/21a, at 3 months postlesion (Horsley-Clarke coordinate from posterior (P) 5.0, P7.5, P6.5 to anterior A5). G, V5/PMLS and area 7 at A5 Horsley-Clarke coordinate. The $C$ and $P$ boxes indicate the two regions of tissue sampling along the dorsoventral axis for a given frontal brain section/visual area: the retinotopic position of the central $(C)$ and peripheral (P) visual field representations in each of the five visual areas. Scale bars: $A, B, 1 \mathrm{~mm}$, C $-G, 2 \mathrm{~mm}$.

Quantitative real-time PCR

All quantitative real-time PCR experiments were performed as described by Cnops et al. (2007) and Hu et al. (2009). The RNA extraction was performed with the Versagene RNA purification kit (Gentra/Biozym) according to the manufacturer's instructions. After biophotometric analysis (Eppendorf, VWR International), RNA samples of identical quantity were reverse transcribed with GeneAmp RNA products con- taining oligo $\mathrm{d}(\mathrm{T})$ primers (Applied Biosystems) at $42^{\circ} \mathrm{C}$ for $60 \mathrm{~min}, 99^{\circ} \mathrm{C}$ for $5 \mathrm{~min}$, and $4^{\circ} \mathrm{C}$ for $10 \mathrm{~min}$. For the real-time PCR experiments we used specific primers (Eurogentec) and TaqMan probes (Applied Biosystems), which were designed with the Primer Express program (Applied Biosystems), based on the cat sequence of gapdh (Forward primer: $5^{\prime}$ tggaaagcccatcaccatct $3^{\prime}$; Reverse primer: 5' caacatactcagcaccagcatca3'; TaqMan probe: $5^{\prime}$ ccaggagcgagatcccgcca3') or zif268 (Forward primer: 5'cttcctcggctgtcaccaa3'; Reverse primer: 5' gggagaaaaggttgttgtcatgt3'; TaqMan probe: 5' cagcgcctcaacagggctttcg3'; Hu et al., 2009). cDNAs were subjected to PCR using the ABI Prism 7000 SDS apparatus in a $25 \mu l$ reaction of $1 \times$ Absolute QPCR Mix (Westburg) with primers at final concentration of $300 \mathrm{~nm}$ and probes of $200 \mathrm{~nm}$. Serial dilutions of control cDNA for generating standard curves were run in duplicate for each gene, whereas target samples were run in triplicate on the same well-plate under standard amplification settings $\left(1 \times 50^{\circ} \mathrm{C}\right.$ for $2 \mathrm{~min}, 1 \times 95^{\circ} \mathrm{C}$ for $10 \mathrm{~min}, 40 \times 95^{\circ} \mathrm{C}$ for $15 \mathrm{~s}$, and $60^{\circ} \mathrm{C}$ for $1 \mathrm{~min}$ ). To compare samples between different runs, we included a reference control in every wellplate. Data were expressed relative to this reference control (Wong and Medrano, 2005). Analysis was performed using ABI Prism 7000 SDS software. The zif268 quantities were normalized to the endogenous housekeeping gene gapdh to account for variability in initial mRNA concentrations and differences in reverse transcription efficiency (Van der Gucht et al., 2003). The relative amount of transcript was quantified by the comparative $C_{\mathrm{t}}$ (cycle threshold) method. To confirm reproducibility, we performed real-time PCR analysis on each cat at least two times.

\section{Verification of the retinal lesions and lesion projection zones}

Apart from the fundus photographs taken prior and after lesion induction, retinal whole mounts were prepared for inspection of the retinal ganglion cell and optical nerve integrity in the surround of the lesion (Fig. $1 A, B$ ), based on neurofilament protein immunocytochemistry (Burnat et al., 2012). Briefly, after an overnight incubation with the primary antibody (SMI-32; 1/1000), the whole mounts were rinsed and incubated with biotinylated goat anti-mouse IgGs (1/200; 30 min; Dako), followed by incubation in an avidin-biotin-horseradish solution according to the manufacturer's recommendations (Vectastain Elite ABC; Vector Laboratories). The reaction product was visualized as a gray-black precipitate using the glucose oxidase-diaminobenzidine-nickel method (Shu et al., 1988; Van der Gucht et al., 2001, 2007). All dilutions and rinsing steps were made in Tris-buffered saline $(0.01 \mathrm{~m}$ Tris, $0.9 \% \mathrm{NaCl}, \mathrm{pH} 7.6)$ containing $0.1 \%$ Triton X-100. The whole mounts were placed on gelatin-coated slides, dehydrated, cleared with xylene, coverslipped, and viewed through a Leitz DM RBE microscope (Leica Leitz).

The extent of the center of the LPZ was verified in all animals participating in the study using in situ hybridization for zif268, based on the low zif268 signal which distinguishes central from peripheral cortical visual field representations, as described previously (Fig. 1C-G; Arckens et al., 2000; Hu et al., 2009). Briefly, a probe complementary to the nucleotides encoding amino acids $2-16$ of the rat zif 268 gene $\left(5^{\prime}\right.$ ccgttgctcagcagcatcatctcctccagyttrgggtagttgtcc $3^{\prime}$ ) was used (Arckens et al., 2000; Van den Bergh et al., 2003; Leysen et al., 2004). After postfixation with $4 \%$ paraformaldehyde in PBS (0.1 M, pH 7.4), slide-mounted sections of cat brain were dehydrated and delipidated. Sections were incubated overnight at $38^{\circ} \mathrm{C}$ with hybridization solution containing the $3^{\prime}$-end terminal transferase 33P-dATP-labeled probes specific for zif268. The next day, sections were thoroughly washed with $1 \times$ standard saline citrate buffer at $43^{\circ} \mathrm{C}$, dehydrated, and exposed to an autoradiographic Bio Max film (Kodak). After 3 weeks, the film was developed following standard procedures. For image production from the autoradiograms, a CanoScan LiDE 600F (Canon) was used. Digital files were adjusted for brightness and contrast in Adobe Photoshop. The images were scanned with a HP Precision scan Scanjet 5300C at a resolution of $1200 \mathrm{dpi}$.

\section{Behavioral training and testing}

For control and RLNaive cats the motion discrimination training consisted of four motion tasks with increasing perceptual difficulty, based on Zapasnik and Burnat (2013, Fig. 3A). Visual training started when the animals were 8 months of age. Cats received food as a reward only during training sessions, with ad libitum access to water in their home cages. 
Body weight was monitored every day before and after training to ensure a healthy condition and kept at $90 \%$ of free-feeding body weight. The cats were trained in the two-choice apparatus with a food reward designed after Berkley (Burnat et al., 2005). The animal, enclosed in a box, viewed the stimuli through two translucent response keys $8.7 \mathrm{~cm}$ wide and $25 \mathrm{~cm}$ high. An occluder between the response keys prevented the animal from seeing the positive $(\mathrm{S}+)$ and negative $(\mathrm{S}-$ ) stimuli together. The viewing distance was $21.5 \mathrm{~cm}$ and both stimuli were placed in the center of the response keys. Pressing the response key for $\mathrm{S}+$ provided a semiliquid reward made of mixed canned and dry animal food. Pressing the Sresponse key was not punished, but prolonged the time interval preceding the next stimulus presentation from 0.5 to $1 \mathrm{~s}$. No correction was allowed. A two-alternative, forced-choice procedure was used in all experiments. Daily sessions consisted of five 20 trial blocks. Percentage of correct responses was calculated for each block. The experiments were performed $5 \mathrm{~d}$ per week for 3 months. To speed up the training compared with the previously reported long durations (Burnat et al., 2002, 2005; Zapasnik and Burnat, 2013), we introduced a less-stringent criterion consisting of $70 \%$ of correct responses calculated from five best blocks, from 1 training day. Only the two cats of the pilot study were trained for a longer time, following the whole procedure as described before (Zapasnik and Burnat, 2013).

$\mathrm{S}+$ and $\mathrm{S}-$ stimuli were displayed simultaneously, with each stimulus being visible behind one of the response keys. The left/right position of the $\mathrm{S}+$ and $\mathrm{S}-$ stimuli was randomized. The stimuli were presented on a computer display (refresh rate $120 \mathrm{~Hz}$ ) with a mean luminance of 38.77 $\mathrm{cd} / \mathrm{m}^{2}$ against a background of $0.03 \mathrm{~cd} / \mathrm{m}^{2}$; measured with a Tektronix $\mathrm{J} 17$ photometer. In motion tasks the $\mathrm{S}+$ stimulus was composed of a random dot kinematogram (RDK) consisting of dots moving coherently upward (all at the same speed and direction) which occupied a circular field of $12.3^{\circ}$ in diameter. The S- stimulus consisted of a downward moving RDK. The size of dots was $0.19^{\circ}$. Four motion tasks were tested, and the difficulty of the tasks was introduced gradually, as described below in the order of testing.

Global motion detection. The S+ consisted of a RDK with upward moving dots ( 10 or $\left.50^{\circ} / \mathrm{s}\right), \mathrm{S}-$ was the identical, but stationary RDK (Fig. 3B).

Fading in direction detection. The $\mathrm{S}+$ consisted of a whole screen upward moving dots (the same as in $\mathrm{S}+$ from the preceding task), $\mathrm{S}-$ was identical but stationary. When a cat received $70 \%$ of correct responses in the course of $1 \mathrm{~d}$, the stationary dots downward motion was faded in with $10 \%$ steps. In total there were 10 downward motion fading steps, as a result at the last step of training all S- dots moved coherently downward. This task was only performed by control and RLNaive cats.

Direction discrimination. The $\mathrm{S}+$ consisted of a RDK with upward moving dots ( 10 or $50 \%$ s). The $\mathrm{S}-\mathrm{RDK}$ dots moved downward with the same velocity as $S+$ dots. In the first level of difficulty the stimuli were presented on the stationary dotted background (Fig. $3 G$, inset). At increasing levels of difficulty, horizontal motion was added to the stationary background dots. Two background dot velocities were tested, 10 and $50 \%$ s (Fig. 3C).

Form-from-velocity detection (threshold measurement). The S+ remained the same. The $\mathrm{S}-$ was no longer a circular RDK, but consisted of background dots moving in the same direction as the dots within $\mathrm{S}+$, but with slower velocity (range from 10 to $40 \%$ s). The velocity of S- dots was adjusted automatically to the cat performance using the staircase method. The $\mathrm{S}+$ was detected on the basis of the velocity difference (Fig. 3D).

Visual acuity testing with sinusoidal gratings. Vertical (S+) and horizontal (S-) gratings with a 50\% luminance contrast between dark and light bars were displayed on an equiluminant background. The spatial frequency of both stimuli was gradually increased from the initial 0.13 $\mathrm{c} / \mathrm{deg}$ level, using the adapting staircase procedure. This procedure was performed only for the two cats participating in the pilot study, and consisted of 1 full training day (120 trials) at the end of the motion training period described in detail by Zapasnik and Burnat (2013), and $14 \mathrm{~d}, 2$ months, and 3 months after retinal lesion induction.

Evaluation of retinal lesion impact upon learned motion tasks. In RLTrained cats, to avoid impact of learning, the same motion tasks (except the Fading in Direction Detection task) learned before lesion induction where tested, but only for $2 \mathrm{~d}$ a week. Testing days consisted of three tasks, presented in order of perceptual difficulty. Each of the tasks was tested in two blocks consisting of 20 trails. When a cat achieved $90-100 \%$ of correct responses in $1 \mathrm{~d}$ of testing, the task was not tested anymore, otherwise tasks were repeatedly tested in random order in a course of a 3-month postlesion recovery period.

\section{Statistics}

Quantitative real-time PCR analysis. As not all comparisons displayed a normal distribution of data points (Shapiro-Wilk test) within a group and with equal variance between groups and given the number of animals per group, nonparametric statistical tests were performed. The KruskalWallis one-way ANOVA on ranks test was used to analyze data of more than two conditions followed by a Tukey post hoc test for all pairwise multiple comparisons. Statistical analyses were performed using Sigma Stat 3.1 (SYSTAT Software).

Behavior. For calculations of standard animal performance, to reduce the daily variability of motivation, the one block with the worst mean percentage of correct responses was excluded and the differences in performance between the groups were calculated using means from the five best blocks. The statistical comparisons were made using the two-level repeated-measures nested one-way ANOVA with post hoc Tukey's multiple-comparison test, $p=0.05$. Days to criterion in the initial Global Motion task, data only from controls and RLNaive were compared and an unpaired $t$ test with Welch correction was applied (Fig. $3 F$ ). In the Results, we describe only data with significant differences of $p=0.05$ calculating $F$ statistics. Statistical analyses were performed using GraphPad Prism 5 software.

For all tests performed on real-time PCR and behavior data, the probability level ( $\alpha$-level was set to 0.05$)$ of $p=0.05$ was accepted as statistically significant. All data are presented as mean \pm SE (SD; Figs. 2, 3).

\section{Results}

In a first set of experiments, we examined the effect of binocular central retinal lesions on the expression of the molecular activity reporter gene zif268. By means of real-time PCR we probed for time- and area-specific changes in the cortical representations of the central and peripheral visual field.

\section{Analysis of $z$ if 268 expression in cat primary visual cortex}

In control subjects the central region of area V1/17 displayed significantly lower zif268 expression than in the peripheral region (Fig. 2A, white bars), confirming previous observations for molecular activity levels in cat primary visual cortex (Hu et al., 2009; Laskowska-Macios et al., 2015b). In cats with retinal lesions (Fig. $2 A$, gray-black bars), this central-peripheral difference was much more pronounced. The center of the LPZ was clearly characterized by a permanently lower zif268 expression compared with the peripheral visual field representation $(p<0.01$, except for $14 \mathrm{~d}$ survival time point where $p<0.05$ ) or to normal tissue, independent of postlesion survival time $(p<0.01)$. Peripheral area 17 also displayed lower zif268 levels $14 \mathrm{~d}$ and 1 month postlesion (Fig. $2 A ; p<0.01$ ), followed by a recovery to normal levels from 3 months postlesion onward.

\section{Analysis of zif268 expression in areas V2/18, V3/19, V4/21a}

Parallel analyses of $z$ if 268 expression in the central and peripheral regions of areas $\mathrm{V} 2 / 18, \mathrm{~V} 3 / 19$, and $\mathrm{V} 4 / 21$ a revealed a similar response to the binocular lesions (Fig. $2 B-D$ ). Just like in area $\mathrm{V} 1 / 17$, the center of the LPZ of areas V2/18, V3/19, and V4/21a displayed a permanently lower zif268 expression compared with the periphery $(p<0.01)$ and to normal control tissue $(p<0.01)$ for all, but area V3/19 at 3 months survival $(p<0.05)$.

The peripheral regions of these areas showed a more varied response. Whereas area V2/18 mimicked area 17 by showing de- 

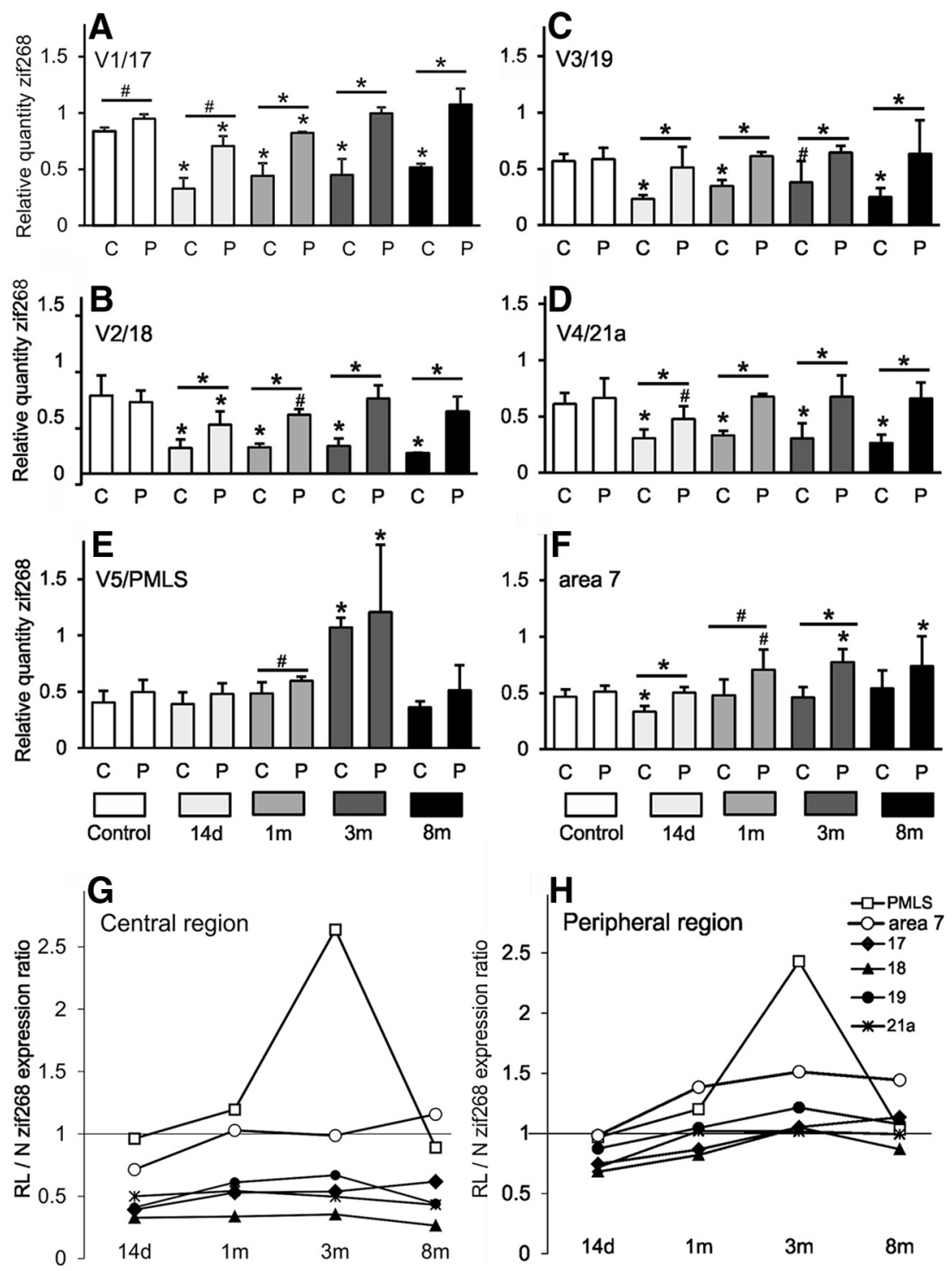

Figure 2. Area-specific zif268 expression profiles in control and retinal lesion cats. Comparison of zif268 expression levels between central $(C)$ and peripheral $(P)$ visual field representations in each of the six visual areas: $(\boldsymbol{A})$ area V1/17, $(\boldsymbol{B})$ area V2/18, $(\boldsymbol{C})$ area V3/19, (D) area V4/21a, (E) area V5/PMLS (posterior medial lateral suprasylvian area), and (F) area 7. The expression of zif268 was analyzed in control (white bars) and retinal lesioned (RL; shades of gray and black) cats with a survival time of $14 \mathrm{~d}, 1 \mathrm{month}$ $(1 \mathrm{~m}), 3$ months $(3 \mathrm{~m})$, and 8 months $(8 \mathrm{~m})$. Note, that four examined visual areas $(\boldsymbol{A}-\boldsymbol{D})$ respond similarly to induction of retinal lesions, but not area V5/PMLS $(\boldsymbol{E})$ and area $7(\boldsymbol{F})$. V5/PMLS did not exhibit the typical decrease in zif268 level in either central or peripheral regions at any of the postlesion survival times. Instead, at 3 months area V5/PMLS shows a distinct upregulation of the zif268 level. Differences in zif268 expression levels are shown: (1) between control versus the corresponding region of each survival RL time point by symbols above the bars and (2) as a central versus peripheral ratio within each condition by lines plus symbols above pairs of bars (indicated by ${ }^{*} p<0.01$ and $\# p<0.05$, Tukey posthoc test). Results are mean + SD. $\boldsymbol{G}, \boldsymbol{H}$, The zif268 expression in the central $(\boldsymbol{G})$ and peripheral $(\boldsymbol{H})$ visual field representation of the same six visual areas in retinal lesion cats as a ratio to the control zif268 values (value 1 on the vertical axis). Note how for both subregions of PMLS (open square) for none of the postlesion survival times (shown on the horizontal axis) a decrease in zif268 is detected, but in contrast a marked upregulation of the zif268 signal at 3 months postlesion only. Area 7 (open circle) also shows quick normalization in the central region and upregulation in the peripheral region.

creased zif268 levels up to 1 month postlesion (for survival time points: $14 \mathrm{~d}, p<0.01 ; 1$ month, $p<0.05$ ), area 19 did not show any peripheral effects, whereas in area 21 a only after $14 \mathrm{~d}$ a decrease in zif268 levels could be discerned compared with normal controls $(p<0.05)$.

\section{Analysis of zif268 expression in area V5/PMLS}

The zif268 profile of area V5/PMLS as a function of postlesion survival time turned out completely different from all other in- vestigated visual areas. The zif268 expression was not significantly altered in the LPZ of area V5/PMLS up to 1 month postlesion (Fig. 2E). At 3 months postlesion a prominent increase in zif268 signal occurred, which was discernable in the central as well as in the peripheral region of area V5/PMLS $(p<0.01)$. Thus, this elevation of zif268 mRNA level was present over the entire extent of area V5/ PMLS and this response was specifically observed 3 months postlesion, because at 8 months postlesion cats again displayed normal zif268 levels in both subregions of V5/PMLS (Fig. 2E). This upregulation at 3 months correlates with the time-point of the restoration of normal activity values in the peripheral regions of area 17 and 18 (Fig. 2A,B).

Analysis of zif 268 expression in area 7 In the central region of area 7, only at $14 \mathrm{~d}$ postlesion, a downregulation of zif 268 signal was detected $(p<0.01)$. From 1 month postlesion on the zif268 expression level normalized (Fig. $2 F$ ). In contrast, in the peripheral visual field representation, we did not detect any sign of a downregulation, at any postlesion survival time, but instead, similar to area V5/PMLS, from 1 month postlesion on an increase in zif268 expression was detected ( 1 month, $p<0.05$; 3 and 8 months, $p<0.01$; Fig. $2 F)$.

\section{Comparison of the subregion-specific lesion impact between visual areas} Figure 2, $G$ and $H$, summarizes the impact of the bilateral central retinal lesions on zif268 activity in the central and peripheral visual field representations for each examined cortical area as a ratio to the normal zif268 values. The ratios $<1$ in Figure $2 G$ visualize the permanently low zif268 expression in the center of the LPZ of areas V1/17, V2/18, V3/19, and area V4/ 21a. For each of the peripheral regions of the same four areas a clearly less pronounced decrease in expression was observed, and only at early postlesion survival times (Fig. $2 H$ ). In contrast, the ratios of 2.5 typify the 3 month time point for area V5/PMLS, highlighting the prominent upregulation of the zif268 expression throughout this area. At earlier time points as well as 8 months postlesion, the zif268 ratios for both the central and peripheral region of area V5/PMLS were close to one. Also the peripheral visual field representation of area 7, from 1 month postlesion onward, showed a stable upregulation of zif268 expression, even at 8 months (Fig. $2 \mathrm{H}$ ), whereas its central region exhibited a zif268 ratio close to 1 , except for the earliest $14 \mathrm{~d}$ time point.

In summary, the $\mathrm{RL} / \mathrm{N}$ ratio evaluation confirms that most visual areas permanently loose normal zif268 expression similarly 
in the very center of the LPZ, except for area V5/PMLS and area 7. Area V5/PMLS clearly exhibits retinotopy-independent hyperactivity specifically at a survival time of 3 months. Because area V5/PMLS is the visual motion V5 homolog in cat, and area 7 has a dominant population of motion-sensitive neurons (Pigarev and Rodionova, 1998), this outcome of the molecular investigations prompted us to look for effects of central retinal lesions, and thus lack of central vision, on motion perception. A pilot study was conducted on two pretrained cats, and instigated further investigations of the impact of retinal lesions on the learning and performance of naive cats for a panel of different motion tasks.

\section{Impact of retinal lesions on pre-learned motion tasks: a pilot study \\ Third postlesion week}

As the only available reports measuring visual performance after retinal lesion concern consequences of either very small binocular lesions ( $\operatorname{circa} 5^{\circ}$; Pasternak et al., 1983) or monocular lesion of increasing diameter (Vandenbussche et al., 1990), we did not know what kind of behavioral deficits to expect. We chose, as a first task, discrimination between a bright and a dark screen with maximal contrast difference. Both cats operated very well in the Berkley box and achieved $85 \%$ and $70 \%$ of correct responses in this task. Next, a global motion detection task was tested (Fig. 3B; $50 \%$ s). Again, both cats easily mastered this task with $90 \%$ and $70 \%$ of correct responses.

Up to 6 weeks postlesion

At 4 weeks of recovery, both cats detected global motion with $100 \%$ of correct responses. At 5 weeks, for the first time, the Direction Detection task $(50 \%$ s, stimuli were presented on the uniform dark background; Fig. 3E) was tested and they performed significantly lower than before lesioning. One day later performance markedly improved, with the highest performance level, even above prelesion performance, reached at 6 weeks postlesion (Fig. 3E).

\section{Later testing and conclusions}

From the 7 th to 12 th week postlesion we tested the response to a battery of stimuli based on decreasing the diameter of the $S+$ and S- RDKs (from 18 to $4^{\circ}$ ), the positioning of the RDK (center or randomized) and finally also different dot velocities (10-200\%s). From all of these variations of the Direction Detection task, only the decrease in velocity to $10 \%$ did impair the performance of the trained lesion cats. Based on these observations we designed the scheme for testing and comparing motion perception in naive cats with and without retinal lesions, as outlined in Materials and Methods.

Finally, visual acuity was measured using stationary sinusoidal gratings. A stable clear drop in performance, independent from time of testing after retinal lesion induction, was determined (from 0.39 and $0.22 \mathrm{c} / \mathrm{deg}$ to 0.10 and 0.10 , respectively) as previously demonstrated for cats with similar retinal lesions, and in line with the lack of central vision (Vandenbussche et al., 1990).

\section{Motion perception after binocular lesions}

Naive lesioned cats versus controls

Before lesion induction the cats were familiarized with the training procedure. After lesion induction, from the beginning of the motion training, it became apparent that the RLNaive cats were very good learners and did not show obvious impairments. In general, RLNaive cats outperformed controls or they performed at a similar level in the motion tasks. In the first Global Motion Detection task $(50 \%)$ RLNaive cats learned to detect motion responses significantly faster than control animals (Fig. 3F; comparison of days to criterion, $p=0.03, \mathrm{df}=6$ ).

In the following tasks, Global Motion detection (10\%), Direction Detection (50 and $10 \%$ s) and Direction Discrimination, RLNaive cats and controls performed equally well. Both groups of cats performed worse for tasks with slower velocity of $10 \%$ compared with the same tasks with velocity of $50 \%$ s. Interestingly, when the stationary background was added to the Direction Discrimination task with slow velocity of $10^{\circ} / \mathrm{s}$, RLNaive cats outperformed controls (Fig. $3 G$; comparison of the mean correct responses from the first day of training, $p=0.012, F=7.06$ ). The Form-from-Velocity Detection task based on figure from background velocity detection again revealed superiority of the RLNaive cats over controls, as they were able to detect figure (RDK) from background motion on the basis of significantly smaller velocity differences than controls (Fig. $3 \mathrm{H}$; comparison of 5 last velocity thresholds for each cat, $p=0.0001, F=21.86$ ). When checking for correlations between performance in the different tasks in RLNaive and control cats, we did not find any, except for a strong correlation between achieved enhanced velocity thresholds and a high level of correct responses for the direction discrimination task in RLNaive cats $(r=0.99)$.

\section{Positive effects of retinal lesions on performance in pretrained cats}

In general, induction of retinal lesions did not affect prelesion motion performance levels. Yet, we did encounter two tasks with significant improvement in performance for RLTrained cats in relation to their prelesion performance. For the Direction Discrimination task $\mathrm{S}+$ and $\mathrm{S}-$ presented on the moving background with high velocity $50 \% \mathrm{~s}(p=0.03)$ and for the Formfrom-Velocity Detection task (Fig. $3 H$; comparison of the 5 last velocity thresholds achieved prior vs after lesion induction, $p=$ $0.002, F=10.91)$ the trained cats consistently showed a better performance upon lesion induction when compared with their prelesion performance. Thus, comparable to naive cats, performance of trained cats improved after induction of central retinal lesions for the direction discrimination and Form-from-Velocity Detection tasks.

\section{Discussion}

We found that the response of areas V5/PMLS and 7 to sudden loss of central vision in adult life is deviating from other visual areas. We demonstrated by means of real-time PCR for the activity reporter gene zif268 that central retinal lesions have a strong depressive effect on the neuronal activity level in the cortical representation of central vision in primary and most of the higher-order visual areas, followed by gradual reactivation. Only motion areas V5/PMLS and 7 stood out by not showing a decrease in zif268 mRNA levels but an upregulation. Behavioral testing demonstrated that motion perception is preserved and even enhanced in our AMD model. We showed here for the first time, that retinal lesioned animals were more inclined to learn motion tasks, and irrespectively of pre-lesioned visual experience, they were more sensitive to higher velocities, confirming enhancement of visual processing in regions selectively tuned to high velocities (V5/PMLS; Villeneuve et al., 2006) and related to visual peripheries (Yu et al., 2010).

\section{Intra-areal horizontal connections likely mediate the cortical reorganization}

Several studies (Kaas et al., 1990; Arckens et al., 2000; Giannikopoulos and Eysel, 2006) showed before that primary areas V1/17 
A Timeline of training
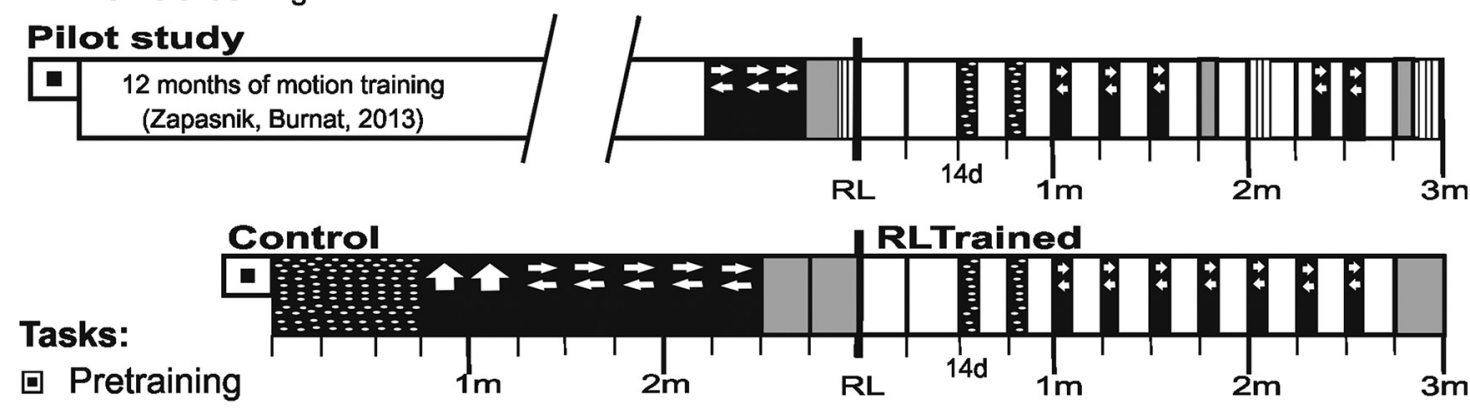

四 Gratings

- Global motion detection

- Fading in Direction

a Direction Discrimination

Form-from-Velocity

B Global Motion Detection

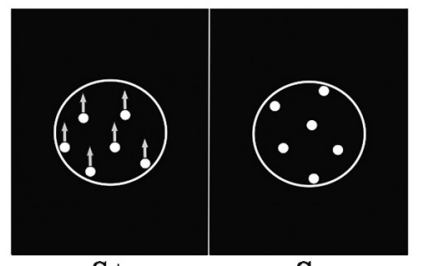

S+

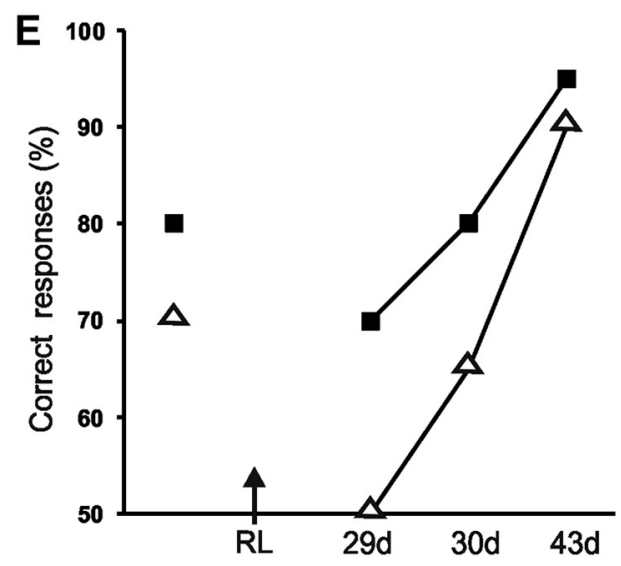

C Direction Discrimination

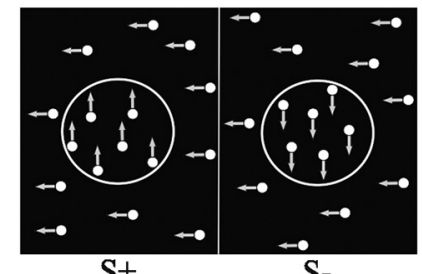

S+

S-

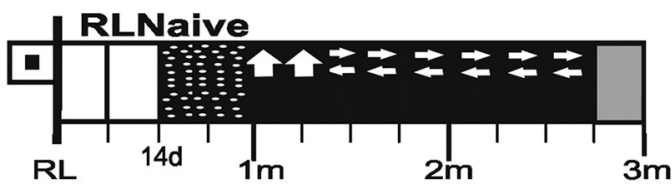

G

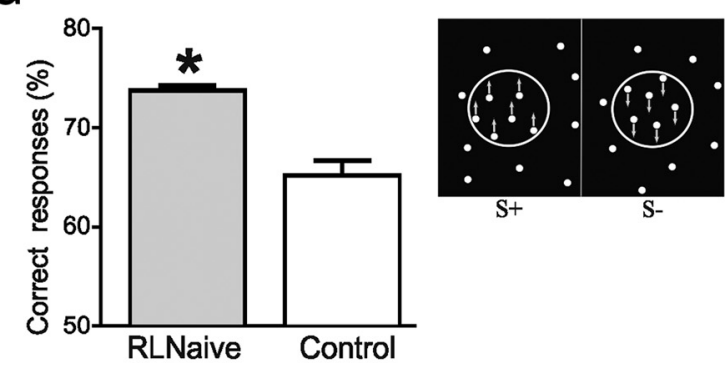

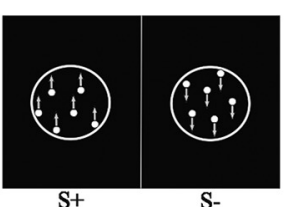

F

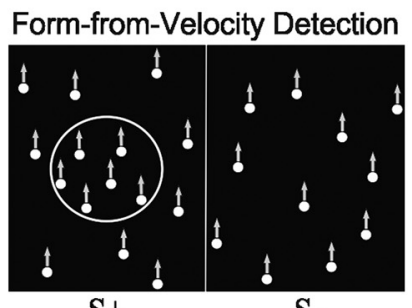

S+

S-

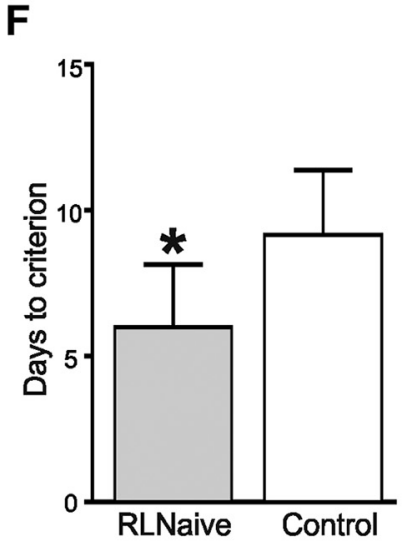

Figure 3. The reinforcement of motion processing upon retinal lesion induction. $\boldsymbol{A}$, Timeline of training for: pilot study, Control/RLTrained cats, and RLNaive cats. RL, retinal lesion induction, followed by $14 \mathrm{~d}$ of recovery period without training. $\boldsymbol{B}-\boldsymbol{D}$, Illustration of the different motion tasks: $(\boldsymbol{B})$ Global Motion Detection task; $(\boldsymbol{C})$ direction discrimination at its most difficult stage, with moving background; easier stages are shown in $\boldsymbol{E}$ with empty and in $(\boldsymbol{G})$ stationary background. $\boldsymbol{D}$, Form-from-Velocity Detection task. Arrows denote direction of motion, and dots denote stationary stimuli, loops encircling $S+$ and $\mathbf{S}-$ are drawn for the presentation. Detailed stimuli descriptions are given in the Materials and Methods section. $\boldsymbol{E}$, Pilot study: correct responses (\%) from two cats in the Direction Discrimination task. Levels before induction of retinal lesion and in 5 and 6 weeks postlesion ( 2 measurements, see Materials and Methods). Note the clear recovery of prelesion correct response levels between the 5 th and 6th week postlesion. $\boldsymbol{F}-\boldsymbol{H}$, Better performance on motion tasks in retinal lesioned than in control cats; only tasks with significant differences are shown: $(\boldsymbol{F})$ days to criterion during first trained Global Motion Detection task (high velocity, $50^{\circ} / \mathrm{s}$ ). RLNaive cats learned the task faster than controls, ${ }^{*} p=0.03$. (Figure legend continues.) 
and V2/18 undergo topographic map reorganization after the induction of retinal lesions of $10^{\circ}$, with the LPZ not reorganizing completely due to the considerable size of the lesions. In agreement with these findings, we showed here that not only areas $\mathrm{V} 1 / 17$ and V2/18, but also V3/19 and V4/21a share a similar time-dependent zif268 expression change, with their centers of LPZ also permanently decreased in activity. The comparable timing of the spatiotemporal reactivation of these visual areas indicates that they reorganize simultaneously.

The intra-areal horizontal connections have been proposed before as most probable anatomical candidates steering the topographical reorganization in V1/17 after binocular retinal lesions (Gilbert et al., 1990; Darian-Smith and Gilbert, 1995; Trachtenberg and Stryker, 2001) as cell recordings have shown that the neurons in the reactivated LPZ of V1/17 maintained their original selectivity concerning orientation, direction, and spatial frequency upon reactivation (Chino et al., 1995). Young et al. (2002) reported supporting data for V1/17 and V2/18 after monocular retinal lesion. They concluded that topographic map remodeling for these two visual areas is mediated in an independent manner by the horizontal fibers, because the neurons of both areas retained their initial unique selectivity features. These observations are in favor of the horizontal connections as anatomical substrate of $\mathrm{V} 1 / 17$ and $\mathrm{V} 2 / 18$ reorganization because these fibers connect neuronal cells with similar tuning preferences organized in cortical columns.

\section{The role of input from higher visual areas}

Although classical studies have provided evidence that the patches formed by horizontal connections exhibit modular specificity by linking columns of neurons with similar response characteristics, such as preferred orientation (Gilbert and Wiesel, 1989; Callaway and Katz, 1990), there is emerging evidence showing that axon clusters in V1 connect to a variety of different orientation domains, not exclusively similarly tuned (Kisvárday et al., 1997; Angelucci et al., 2002; Martin et al., 2014). To become active, such differently tuned-organized horizontal connections need to be strengthened, most likely by feedback inputs from higher-order visual areas as proposed by fMRI (Williams et al., 2008) and electrophysiological studies (Galuske et al., 2002).

\section{Motion perception facilitation by central retinal lesions: feedback inputs}

The motion-sensitive area V5/PMLS did not display a LPZ, most likely due to the size of RFs, which in cat can far exceed $20^{\circ}$ (Djavadian and Harutiunian-Kozak, 1983; Zumbroich et al., 1986). Moreover, our zif268 data demonstrated a hyperactivity period for this area. Analogously, an fMRI case report of one macaque monkey who developed an AMD condition showed, similar to our findings, specific activation of area V5/MT compared with control subjects (Shao et al., 2013).

We compared V5/PLMS hyperactivity with zif268 activation to another higher-order visual area, V4/21a, engaged in form processing (Dreher et al., 1993, 1996; Lomber, 2001). The real-

\section{$\leftarrow$}

(Figure legend continued.) G, Correct responses (\%) in the Direction Discrimination task with slow velocity $\left(10^{\circ} / \mathrm{s}\right)$ : RLNaive cats outperformed controls, ${ }^{*} p=0.012$. $\boldsymbol{H}$, Velocity threshold in the Form-from-Velocity Detection task (dots within $\mathrm{S}+$ circle move with $40^{\circ} / \mathrm{s}$ velocity, the background velocity adapts to the performance). Control cats reached a significantly lower background velocity threshold, ${ }^{* *} p<0.0001$. Performance of naive before retinal lesion (RLNaive, gray bars), control naive (white bars), and cats trained before retinal lesion induction (RLTrained, hatched bar). Results are mean + SD. time PCR analysis showed no signs of such hyperactivity. On the contrary, the postlesion effects on the zif268 expression in V4/21a mirrored those of areas V1/17, V2/18, and V3/19. These results suggest that motion processing is amplified over form processing after central retinal lesions. Our results indeed revealed facilitation of motion perception in naive animals in the first weeks after lesion induction. The timing of the increase of zif268 expression in central as well as peripheral area V5/PMLS correlates well with the time-point of restoration of normal values of molecular activity in the peripheral region of areas V1/17 and V2/18, suggesting that V5/PMLS might modulate the reorganization of the peripheral part of these areas via feedback inputs. Additionally, the high SDs in the peripheral region of V5/PMLS at 3 months postlesion may be caused by plasticity of peripheral area 17 and 18 , as visible by time-dependent zif268 expression, enhancing reciprocal connections with the peripheral region of V5/PMLS and proceeding with somewhat different speed in each cat.

We are in favor of the feedback hypothesis because neuronal activity in cat V5/PMLS does depend not only upon input from the primary visual cortex, as it receives direct input via the pulvinar complex (Ouellette and Casanova, 2006; Piché al., 2013) and lesions of primary visual cortex leave response properties of V5/ PMLS neurons relatively unchanged (Spear and Baumann, 1979; Guido et al., 1990). Additionally, developmental studies put monkey $\mathrm{V} 5$ in a position parallel to $\mathrm{V} 1$, as both areas mature in a similar time frame (Bourne and Rosa, 2006) and develop independently (Bottari et al., 2015). Additional evidence for V5 acting independently from V1, comes from blind human subjects where V5 is activated by the motion component in auditory stimuli (Saenz et al., 2008).

\section{Activity restoration of peripheral visual field representation}

In contrast to the permanently deprived LPZ center, the peripheral visual field representations of areas V1-V4 exhibited a timedependent restoration of the prelesion condition. This is most probably due to the fact that the spared peripheral retina is dominated by the motion-sensitive Y-pathway, with V2/18 and V5/ PMLS being mostly driven by Y-type inputs (Wang et al., 1997; Vajda et al., 2004). After induction of central retinal lesions the topographic reorganization leads to over-representation of the intact nondeprived peripheral retina, for which the Y-pathway might be the driving force. These findings correspond to previous data at retina level in the context of pattern vision deprivationinduced adaptations to Y-type retinal ganglion cells (Burnat et al., 2012). Based on our cortical development data, it appears that peripheral representations are particularly prompt to plastic rearrangements (Laskowska-Macios et al., 2015a,b; for review, see Burnat, 2015). In line, in deaf subjects the peripheral visual cortex shows stronger sensitivity to visual stimulation, than in normal hearing people (Bavelier et al., 2000; Merabet and Pascual-Leone, 2010). Codina et al. (2017) prove that not only congenital deafness triggers a plastic response within the peripheral visual field, but also extensive training of sign language in normal hearing sign language interpreters does.

Cortical regions that previously received inputs from the fovea become activated by peripheral retinal stimulation from the border of the LPZ inward. fMRI examinations of adult and juvenile macular degeneration (MD) patients also show such plastic change in excitability of the LPZ, which is normally responsive only to foveal stimulation, but in patients is activated by visual peripheries (Baker et al., 2005; Masuda et al., 2008).

MD patients with central retinal lesions often develop an eccentric viewing strategy as substitute for the damaged fovea, 
adapting a so-called preferred retinal locus (PRL) where they spontaneously choose to fixate (Cheung and Legge, 2005; Schumacher et al., 2008). Important to our understanding of the plastic mechanisms underlying the recovery after central retinal lesions, most of the MD patients tend to develop a PRL within the lower visual field (Guez et al., 1993), which is involved in motion perception, in contrast to the upper visual field involved in form perception (Zito et al., 2016). Furthermore, the functional importance of processing within the lower visual field is strengthened by attention (He et al., 1996), driven by extrastriate visual cortical areas (Martínez et al., 1999) and it can be even modulated by direct cortical electrical microstimulation of V5/MT in monkeys (Fetsch et al., 2014). Together with the findings showing how sustained attention helps MD patients with solving visual tasks (Altpeter et al., 2000), we suggest that feedback connections are a potential source of reestablishing the visual activity within the border of the LPZ of the different visual areas. Most likely attention-driven feedback can strengthen the bottom-up inputs of peripheral stimuli, as also postulated by fMRI-based data in normally sighted and MD patients (Baker et al., 2005; Masuda et al., 2008; Williams et al., 2008). As shown recently by TMS, application of a protocol that strengthens feedback connections from V5 to V1 leads to motion perception enhancement (Romei et al., 2016). This interpretation also fits with our observations for area 7 . Area 7 was recently described to send strong feedback to areas V1/17 and V2/18 (Yang et al., 2016), and to display visual responses enhanced by attention (Pigarev and Rodionova, 1998). V1/17 and V2/18 are the two areas in which the peripheral representations fully recovered by 3 month postlesion, possibly based on the sustained attention-strengthened feedback inputs from area 7.

In conclusion, we have demonstrated that the cortical activity of all primary and higher-order visual areas under investigation is affected by central retinal lesions. Whereas the center of the LPZ of visual areas V1-V4 remained permanently deprived, the peripheral visual field representations exhibited a time-dependent restoration of the prelesion condition. Only area V5/PMLS did not show a LPZ and was characterized by a transient hyperactivity period. We propose that, next to horizontal intracortical connections, also inter-areal feedback connections play a role in the plasticity-mediated cortical reorganization, as we show here for motion perception in the context of central retinal lesions.

\section{References}

Abe H, McManus JN, Ramalingam N, Li W, Marik SA, Meyer zum Alten Borgloh SM, Gilbert CD (2015) Adult cortical plasticity studied with chronically implanted electrode arrays. J Neurosci 35:2778-2790. CrossRef Medline

Altpeter E, Mackeben M, Trauzettel-Klosinski S (2000) The importance of sustained attention for patients with maculopathies. Vision Res 40:15391547. CrossRef Medline

Angelucci A, Bullier J (2003) Reaching beyond the classical receptive field of V1 neurons: horizontal or feedback axons? J Physiol Paris 97:141-154. CrossRef Medline

Angelucci A, Levitt JB, Walton EJ, Hupe JM, Bullier J, Lund JS (2002) Circuits for local and global signal integration in primary visual cortex. J Neurosci 22:8633-8646. Medline

Arckens L (2006) The molecular biology of sensory map plasticity in adult mammals. In: Plasticity in the visual system: from genes to circuits (Pinaud R, Tremere LA, de Weerd P, eds), pp 181-203. New York: Springer Science and Business Media.

Arckens L, Van Der Gucht E, Eysel UT, Orban GA, Vandesande F (2000) Investigation of cortical reorganization in area 17 and nine extrastriate visual areas through the detection of changes in immediate early gene expression as induced by retinal lesions. J Comp Neurol 425:531-544. CrossRef Medline
Baker CI, Peli E, Knouf N, Kanwisher NG (2005) Reorganization of visual processing in macular degeneration. J Neurosci 25:614-618. CrossRef Medline

Bavelier D, Tomann A, Hutton C, Mitchell T, Corina D, Liu G, Neville H (2000) Visual attention to the periphery is enhanced in congenitally deaf individuals. J Neurosci 20:RC93. Medline

Bottari D, Troje NF, Ley P, Hense M, Kekunnaya R, Röder B (2015) The neural development of the biological motion processing system does not rely on early visual input. Cortex 71:359-367. CrossRef Medline

Bourne JA, Rosa MG (2006) Hierarchical development of the primate visual cortex, as revealed by neurofilament immunoreactivity: early maturation of the middle temporal area (MT). Cereb Cortex 16:405-414. CrossRef Medline

Buonomano DV, Merzenich MM (1998) Cortical plasticity: from synapses to maps. Annu Rev Neurosci 21:149-186. CrossRef Medline

Burnat K (2015) Are visual peripheries forever young? Neural Plast 2015: 307929. CrossRef Medline

Burnat K, Vandenbussche E, Zernicki B (2002) Global motion detection is impaired in cats deprived early of pattern vision. Behav Brain Res 134:5965. CrossRef Medline

Burnat K, Stiers P, Arckens L, Vandenbussche E, Zernicki B (2005) Global form perception in cats early deprived of pattern vision. Neuroreport 16:751-754. CrossRef Medline

Burnat K, Van Der Gucht E, Waleszczyk WJ, Kossut M, Arckens L (2012) Lack of early pattern stimulation prevents normal development of the alpha $(\mathrm{Y})$ retinal ganglion cell population in the cat. J Comp Neurol 520:2414-2429. CrossRef Medline

Callaway EM, Katz LC (1990) Emergence and refinement of clustered horizontal connections in cat striate cortex. J Neurosci 10:1134-1153. Medline

Cheung SH, Legge GE (2005) Functional and cortical adaptations to central vision loss. Vis Neurosci 22:187-201. CrossRef Medline

Chino YM, Kaas JH, Smith EL 3rd, Langston AL, Cheng H (1992) Rapid reorganization of cortical maps in adult cats following restricted deafferentation in retina. Vision Res 32:789-796. CrossRef Medline

Chino YM, Smith EL 3rd, Kaas JH, Sasaki Y, Cheng H (1995) Receptivefield properties of deafferentated visual cortical neurons after topographic map reorganization in adult cats. J Neurosci 15:2417-2433. Medline

Cnops L, Hu TT, Eysel UT, Arckens L (2007) Effect of binocular retinal lesions on CRMP2 and CRMP4 but not Dyn I and Syt I expression in adult cat area 17. Eur J Neurosci 25:1395-1401. CrossRef Medline

Codina CJ, Pascalis O, Baseler HA, Levine AT, Buckley D (2017) Peripheral visual reaction time is faster in deaf adults and British sign language interpreters than in hearing adults. Front Psychol 8:50. CrossRef Medline

Connolly JD, Hashemi-Nezhad M, Lyon DC (2012) Parallel feedback pathways in visual cortex of cats revealed through a modified rabies virus. J Comp Neurol 520:988-1004. CrossRef Medline

Darian-Smith C, Gilbert CD (1995) Topographic reorganization in the striate cortex of the adult cat and monkey is cortically mediated. J Neurosci 15:1631-1647. Medline

Djavadian RL, Harutiunian-Kozak BA (1983) Retinotopic organization of the lateral suprasylvian area of the cat. Acta Neurobiol Exp (Wars) 43: 251-262. Medline

Dreher B, Michalski A, Ho RH, Lee CW, BurkeW (1993) Processing of form and motion in area 21a of cat visual cortex. Vis Neurosci 10:93-115. CrossRef Medline

Dreher B, Wang C, Turlejski KJ, Djavadian RL, Burke W (1996) Areas PMLS and 21a of cat visual cortex: two functionally distinct areas. Cereb Cortex 6:585-599. CrossRef Medline

Dreher B, Burke W, Calford MB (2001) Cortical plasticity revealed by circumscribed retinal lesions or artificial scotomas. Prog Brain Res 134:217246. CrossRef Medline

Eysel UT, Gonzalez-Aguilar F, Mayer U (1980) A functional sign of reorganization in the visual system of adult cats: lateral geniculate neurons with displaced receptive fields after lesions of the nasal retina. Brain Res 181: 285-300. CrossRef Medline

Eysel UT, Gonzalez-Aguilar F, Mayer U (1981) Time-dependent decrease in the extent of visual deafferentation in the lateral geniculate nucleus of adult cats with small retinal lesions. Exp Brain Res 41:256-263. Medline

Eysel UT, Schweigart G, Mittmann T, Eyding D, Qu Y, Vandesande F, Orban G, Arckens L (1999) Reorganization in the visual cortex after retinal and cortical damage. Restor Neurol Neurosci 15:153-164. Medline 
Fetsch CR, Kiani R, Newsome WT, Shadlen MN (2014) Effects of cortical microstimulation on confidence in a perceptual decision. Neuron 83: 797-804. CrossRef Medline

Galuske RA, Schmidt KE, Goebel R, Lomber SG, Payne BR (2002) The role of feedback in shaping neural representations in cat visual cortex. Proc Natl Acad Sci U S A 99:17083-17088. CrossRef Medline

Giannikopoulos DV, Eysel UT (2006) Dynamics and specificity of cortical map reorganization after retinal lesions. Proc Natl Acad Sci U S A 103: 10805-10810. CrossRef Medline

Gilbert CD, Li W (2012) Adult visual cortical plasticity. Neuron 75:250264. CrossRef Medline

Gilbert CD, Sigman M (2007) Brain states: top-down influences in sensory processing. Neuron 54:677-696. CrossRef Medline

Gilbert CD, Wiesel TN (1989) Columnar specificity of intrinsic horizontal and corticocortical connections in cat visual cortex. J Neurosci 9:24322442. Medline

Gilbert CD, Wiesel TN (1992) Receptive field dynamics in adult primary visual cortex. Nature 356:150-152. CrossRef Medline

Gilbert CD, Hirsch JA, Wiesel TN (1990) Lateral interactions in visual cortex. Cold Spring Harb Symp Quant Biol 55:663-677. CrossRef Medline

Guez JE, Le Gargasson JF, Rigaudiere F, O’Regan JK (1993) Is there a systematic location for the pseudo-fovea in patients with central scotoma? Vision Res 33:1271-1279. CrossRef Medline

Guido W, Tong L, Spear PD (1990) Afferent bases of spatial- and temporalfrequency processing by neurons in the cat's posteromedial lateral suprasylvian cortex: effects of removing areas 17, 18, and 19. J Neurophysiol 64:1636-1651. Medline

He S, Cavanagh P, Intriligator J (1996) Attentional resolution and the locus of visual awareness. Nature 383:334-337. CrossRef Medline

Hu TT, Laeremans A, Eysel UT, Cnops L, Arckens L (2009) Analysis of c-fos and zif268 expression reveals time-dependent changes in activity inside and outside the lesion projection zone in adult cat area 17 after retinal lesions. Cereb Cortex 19:2982-2992. CrossRef Medline

Hu TT, Van den Bergh G, Thorrez L, Heylen K, Eysel UT, Arckens L (2011) Recovery from retinal lesions: molecular plasticity mechanisms in visual cortex far beyond the deprived zone. Cereb Cortex 21:2883-2892. CrossRef Medline

Kaas JH, Krubitzer LA, Chino YM, Langston AL, Polley EH, Blair N (1990) Reorganization of retinotopic cortical maps in adult mammals after lesions of the retina. Science 248:229-231. CrossRef Medline

Kisvárday ZF, Tóth E, Rausch M, Eysel UT (1997) Orientation-specific relationship between populations of excitatory and inhibitory lateral connections in the visual cortex of the cat. Cereb Cortex 7:605-618. CrossRef Medline

Kossut M, Hand PJ, Greenberg J, Hand CL (1988) Single vibrissal cortical column in SI cortex of rat and its alterations in neonatal and adult vibrissa-deafferented animals: a quantitative 2DG study. J Neurophysiol 60:829-852. Medline

Laskowska-Macios K, Nys J, Hu TT, Zapasnik M, Van der Perren A, Kossut M, Burnat K, Arckens L (2015a) Binocular pattern deprivation interferes with the expression of proteins involved in primary visual cortex maturation in the cat. Mol Brain 8:48. CrossRef Medline

Laskowska-Macios K, Zapasnik M, Hu TT, Kossut M, Arckens L, Burnat K (2015b) Zif268 mRNA expression patterns reveal a distinct impact of early pattern vision deprivation on the development of primary visual cortical areas in the cat. Cereb Cortex 25:3515-3526. CrossRef Medline

Leysen I, Van der Gucht E, Eysel UT, Huybrechts R, Vandesande F, Arckens L (2004) Time-dependent changes in the expression of the MEF2 transcription factor family during topographic map reorganization in mammalian visual cortex. Eur J Neurosci 20:769-780. CrossRef Medline

Lomber SG (2001) Behavioral cartography of visual functions in cat parietal cortex: areal and laminar dissociations. Prog Brain Res 134:265-284. CrossRef Medline

Martin KA, Roth S, Rusch ES, Hubel DH, Wiesel TN, Rockland KS, et al. (2014) Superficial layer pyramidal cells communicate heterogeneously between multiple functional domains of cat primary visual cortex. Nat Commun 5:5252. CrossRef Medline

Martínez A, Anllo-Vento L, Sereno MI, Frank LR, Buxton RB, Dubowitz DJ, Wong EC, Hinrichs H, Heinze HJ, Hillyard SA. (1999) Involvement of striate and extrastriate visual cortical areas in spatial attention. Nat Neurosci 2:364-369. CrossRef Medline

Masuda Y, Dumoulin SO, Nakadomari S, Wandell BA (2008) V1 projection zone signals in human macular degeneration depend on task, not stimulus. Cereb Cortex 18:2483-2493. CrossRef Medline

Merabet LB, Pascual-Leone A (2010) Neural reorganization following sensory loss: the opportunity of change. Nat Rev Neurosci 11:44-52. CrossRef Medline

Olson CR, Lawler K (1987) Cortical and subcortical afferent connections of a posterior division of feline area 7 (area 7p). J Comp Neurol 259:13-30. CrossRef Medline

Ouellette BG, Casanova C (2006) Overlapping visual response latency distributions in visual cortices and LP-pulvinar complex of the cat. Exp Brain Res 175:332-341. CrossRef Medline

Pasternak T, Merigan WH, Flood DG, Zehl D (1983) The role of area centralis in the spatial vision of the cat. Vision Res 23:1409-1416. CrossRef Medline

Payne BR (1993) Evidence for visual cortical area homologs in cat and macaque monkey. Cereb Cortex 3:1-25. CrossRef Medline

Piché M, Thomas S, Casanova C (2013) Spatiotemporal profiles of neurons receptive fields in the cat posteromedial lateral suprasylvian cortex. Neuroscience 248:319-332. CrossRef Medline

Pigarev IN, Rodionova EI (1998) Two visual areas located in the middle suprasylvian gyrus (cytoarchitectonic field 7) of the cat's cortex. Neuroscience 85:717-732. CrossRef Medline

Romei V, Chiappini E, Hibbard PB, Avenanti A (2016) Empowering reentrant projections from V5 to V1 boosts sensitivity to motion. Curr Biol 26:2155-2160. CrossRef Medline

Rosenquist AC (1985) Connections of visual cortical areas in the cat. In: Cerebral cortex (Peters A, Jones E, eds), pp 81-117. New York: Plenum Press.

Saenz M, Lewis LB, Huth AG, Fine I, Koch C (2008) Visual motion area $\mathrm{MT}+/ \mathrm{V} 5$ responds to auditory motion in human sight-recovery subjects. J Neurosci 28:5141-5148. CrossRef Medline

Sammons RP, Keck T (2015) Adult plasticity and cortical reorganization after peripheral lesions. Curr Opin Neurobiol 35:136-141. CrossRef Medline

Schumacher EH, Jacko JA, Primo SA, Main KL, Moloney KP, Kinzel EN, Ginn J (2008) Reorganization of visual processing is related to eccentric viewing in patients with macular degeneration. Restor Neurol Neurosci 26:391-402. Medline

Shao Y, Keliris GA, Papanikolaou A, Fischer MD, Zobor D, Jägle H, Logothetis NK, Smirnakis SM (2013) Visual cortex organisation in a macaque monkey with macular degeneration. Eur J Neurosci 38:3456-3464. CrossRef Medline

Sherk H (2010) Evidence regarding the integrity of the posterior medial lateral suprasylvian visual area in the cat. J Comp Neurol 518:3343-3358. CrossRef Medline

Shu SY, Ju G, Fan LZ (1988) The glucose oxidase-DAB-nickel method in peroxidase histochemistry of the nervous system. Neurosci Lett 85:169171. CrossRef Medline

Spear PD, Baumann TP (1979) Effects of visual cortex removal on receptive-field properties of neurons in lateral suprasylvian visual area of the cat. J Neurophysiol 42:31-56. Medline

Trachtenberg JT, Stryker MP (2001) Rapid anatomical plasticity of horizontal connections in the developing visual cortex. J Neurosci 21:3476-3482. Medline

Vajda I, Lankheet MJ, Borghuis BG, van de Grind WA (2004) Dynamics of directional selectivity in area 18 and PMLS of the cat. Cereb Cortex 14: 759-767. CrossRef Medline

Van den Bergh G, Clerens S, Cnops L, Vandesande F, Arckens L (2003) Fluorescent two-dimensional difference gel electrophoresis and mass spectrometry identify age-related protein expression differences for the primary visual cortex of kitten and adult cat. J Neurochem 85:193-205. CrossRef Medline

Van der Gucht E, Vandesande F, Arckens L (2001) Neurofilament protein: a selective marker for the architectonic parcellation of the visual cortex in adult cat brain. J Comp Neurol 441:345-368. CrossRef Medline

Van der Gucht E, Massie A, De Klerck B, Peeters K, Winters K, Gerets HH, Clerens S, Vandesande F, Arckens L (2003) Molecular cloning and differential expression of the cat immediate early gene c-fos. Brain Res Mol Brain Res 111:198-210. CrossRef Medline

Van der Gucht E, Hof PR, Van Brussel L, Burnat K, Arckens L (2007) Neurofilament protein and neuronal activity markers define regional archi- 
tectonic parcellation in the mouse visual cortex. Cereb Cortex 17:28052819. CrossRef Medline

Vandenbussche E, Eysel UT, Orban GA (1990) Influence of retinal lesions on grating acuity of the cat. Neurosci Lett 110:249-255. CrossRef Medline

Vanduffel W, Vandenbussche E, Singer W, Orban GA (1995) Metabolic mapping of visual areas in the behaving cat: $\mathrm{A}\left[{ }^{14} \mathrm{C}\right] 2$-deoxyglucose study. J Comp Neurol 354:161-180. CrossRef Medline

Villeneuve MY, Ptito M, Casanova C (2006) Global motion integration in the postero-medial part of the lateral suprasylvian cortex in the cat. Exp Brain Res 172:485-497. CrossRef Medline

Waleszczyk WJ, Wang C, Young JM, Burke W, Calford MB, Dreher B (2003) Laminar differences in plasticity in area 17 following retinal lesions in kittens or adult cats. Eur J Neurosci 17:2351-2368. CrossRef Medline

Wang C, Dreher B, Huxlin KR, Burke W (1997) Excitatory convergence of Y and non-Y information channels on single neurons in the PMLS area, a motion area of the cat visual cortex. Eur J Neurosci 9:921-933. CrossRef Medline

Williams MA, Baker CI, Op de Beeck HP, Shim WM, Dang S, Triantafyllou C, Kanwisher N (2008) Feedback of visual object information to foveal retinotopic cortex. Nat Neurosci 11:1439-1445. CrossRef Medline
Wong ML, Medrano JF (2005) Real-time PCR for mRNA quantitation. Biotechniques 39:75-85. CrossRef Medline

Yang X, Ding H, Lu J (2016) Feedback from visual cortical area 7 to areas 17 and 18 in cats. Neuroscience 312:190-200. CrossRef Medline

Young JM, Waleszczyk WJ, Burke W, Calford MB, Dreher B (2002) Topographic reorganization in area 18 of adult cats following circumscribed monocular retinal lesions in adolescence. J Physiol 541:601-612. CrossRef Medline

Yu HH, Verma R, Yang Y, Tibballs HA, Lui LL, Reser DH, Rosa MG (2010) Spatial and temporal frequency tuning in striate cortex: functional uniformity and specializations related to receptive field eccentricity. Eur J Neurosci 31:1043-1062. CrossRef Medline

Zapasnik M, Burnat K (2013) Binocular pattern deprivation with delayed onset has impact on motion perception in adulthood. Neuroscience 255: 99-109. CrossRef Medline

Zito GA, Cazzoli D, Müri RM, Mosimann UP, Nef T (2016) Behavioral differences in the upper and lower visual hemifields in shape and motion perception. Front Behav Neurosci 10:128. CrossRef Medline

Zumbroich TJ, von Grünau M, Poulin C, Blakemore C (1986) Differences of visual field representation in the medial and lateral banks of the suprasylvian cortex (PMLS/PLLS) of the cat. Exp Brain Res 64:77-93. CrossRef Medline 